\title{
Application and study of Shield Mule
}

\author{
WU Wei-cheng ${ }^{1, a}$, SU Fang ${ }^{1, b}$, WANG Chen-sheng ${ }^{1, c^{*}}$ \\ ${ }^{1}$ Caol School, Shanxi Datong Uniwersity, Shanxi Datong,037003, china \\ adtdxwwc@163.com, ${ }^{\mathrm{b}} 13934761850 @ 126 . c o m,{ }^{\circ} 15835218961 @ 163 . c o m$
}

Keywords: Shield mule; Face moving; Fafety.

Abstract. Through the research of the main parameters, performance and advantages of shield mule, and the application process of working face equipment moving process of the ultra thick seam with full thick low caving coal mining technology in Tongxin mine, solved that has been existed since as the retreat time longer, the process complex, the cost of supporting large. Results show that the device performance is stable, safe and reliable, support withdrawal speed, good effect.

\section{Introduction}

Since its launch in 2009, Tongxin caves the north a plate of district 8101, 8100, 8106, 8107, 8105 and 8104 six working face with fully mechanized sub-level caving mining method。

Since the Tongxin builded, mining equipment withdrawal process always adopt the method of multi-channel single shield. For retracement process of shield in working face, uses the prop pulling hoist, and rail transport. By prop pulling hoist first pressed roof support evacuate to the front part of your work space under state of auxiliary transportation in orbit, and then, to adjust the direction, continue to be prop pulling hoist will support from face to face transport gateway, truck rubber-tyred stents in working face transport gateway will withdraw support away.

As with Tongxin mine for the super thick coal seam in a mining thick low all the caving mining technology, the upper bracket top-coal and breakage of the immediate roof will be tighter stents, and its clamping force $4230 \mathrm{kN} \sim 4760 \mathrm{kN}$, its produce friction resistance between the $2200 \mathrm{kN} \sim 2400 \mathrm{kN}$. Therefore, during the period of working face equipment moved from overpressure frame, roof leakage accident occurred, affected the moving speed and the mine safety production. Especially prop-pulling hoist using rope, rope skipping and broken rope accident happens often, poses a potential threat to personnel safety. To solve the hydraulic support, a series of problems in the process of retreat with the coal group company joint pass at is with the coal group specific heavy-duty hydraulic support retracement crane is developed.

\section{Introduction to the shield mule}

There is single arm work mechanism, hydraulic transmission system, diesel engine power drives, crawler walking and heavy duty rack, etc., in structure of this type shield mule, so the shield mule has good stability of whole machine, with great strength, swing, reliable and flexible motion, climbing ability is strong, good adaptability, fast shelves, etc. Specific parameters of shield mule is shown in table 1.

Table 1 Main parameters of shield mule

\begin{tabular}{cc}
\hline Project & Values \\
\hline Height $\times$ Width $\times$ Length & $1300 \mathrm{~mm} \times 3100 \mathrm{~mm} \times 10600 \mathrm{~mm}$ \\
Weight & $50000 \mathrm{~kg}$ \\
Speed of moving & $3.4 \mathrm{~km} / \mathrm{h}($ light path $)$ \\
Maximum longitudinal grade & $16^{\circ}(1: 3.5)$ \\
Maximum lateral grade & $6.9^{\circ}(1: 8.75)$ \\
Load turn $90^{\circ}$ & $5 \mathrm{~m}$ \\
Straight reverse turn & $3.5 \mathrm{~m}$ \\
Minimum height of roadway & $2 \mathrm{~m}$ \\
Boom working range & up $75^{\circ} ;$ right and left $60^{\circ}$ \\
\hline
\end{tabular}


The shield mule just needs a driver and an auxiliary operators. It can lift of $0 \sim 85$ tons stents and other heavy equipment. The shield mule's picture as shown in Fig.1.

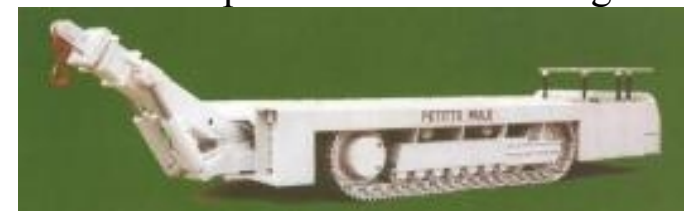

Fig.1 The shield mule

\section{Hydraulic support retracement process}

Due to the shield mule walking speed slower, there use two hydraulic support bull of walk fast clam butt lift bracket truck to transport from the garage to working face, as does not affect the normal traffic.

The working process of the shield mule and the work cycle is as follows Fig.2:

\section{In place}

Move forward to front-end working place of prepared hydraulic support before starting the shield mule. Ensure the reasonable position of the shield mule and hydraulic support, as shown in Fig.2 (a).

\section{Support}

Start the hydraulic cylinder control handle, and the four support hydraulic cylinder of shield mule out of contact with the floor, reach early supporting force, make the shield mule stability in a fixed position, prepare for extraction frame.

\section{Hanging}

Oscillating single arm working mechanism, and making it to the appropriate location, than puting the drag chain connected to the bracket front-end, further prepared to pump. As shown in Fig. 2 (b).

\section{Extracting}

Startting lifting hydraulic cylinder, up to hydraulic support front hanging off the ground, and then start rotating hydraulic cylinder, oscillating single arm working mechanism, dragging support, which make it under the compression state, from the original work position to the shelves space, at the same time hydraulic support at no load condition. In support to the no load state, generally have implementation supports boom turned to $30^{\circ} \sim 60^{\circ}$. As shown in Fig.2 (c).

\section{Turning}

After extracting the hydraulic support to the open space, pack up the supporting hydraulic cylinder, starting the shield mule moved backward, implementing all stents to reach the designated position. In the process of steering, prevent the extrusion and friction with the adjacent frame. As shown in Fig. 2 (d).

\section{Dragging}

Moving the shield mule, and dragging the hydraulic support to front end of working face, then placing hydraulic support in the middle position of roadway, and can making sure the shield mule has enough space from the side into the face again. As shown in Fig.2 (e,f).

\section{Reset}

Removing the links of the shield mule and hydraulic support, and starting the shield mule, once again into the working face from the side, back to a support position of the evacuation, begin the next bracket out of circulation. As shown in Fig.2 (g).

Back to the suction rack position next, begin the next support filling process, this cycle, until will all stents back to leave.

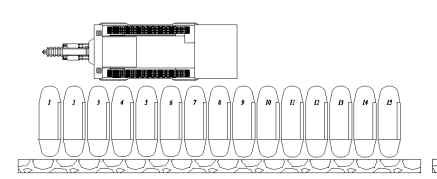

(a) In place

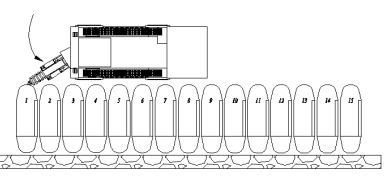

(b) Hanging

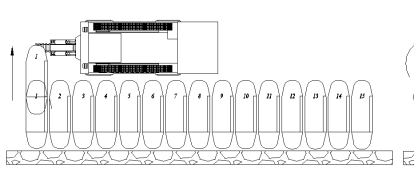

(c) Extracting



(d) Turning 


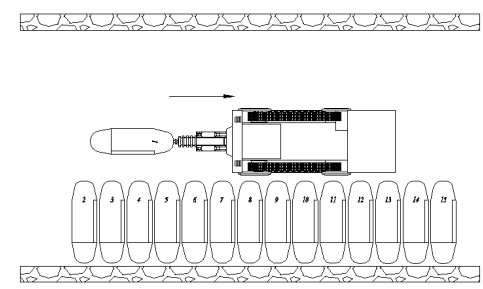

(e) Dragging

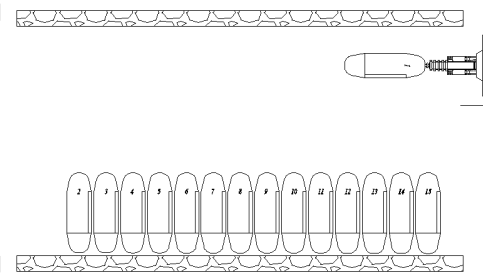

(f) Dragging

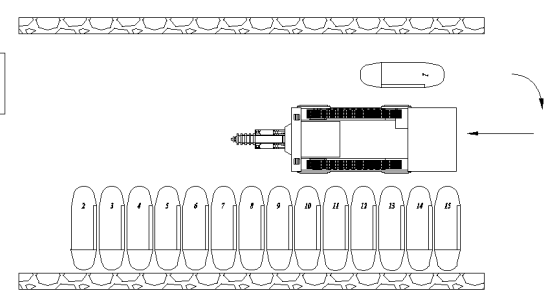

(g) Reset

Fig. 2 The working process of the shield mule and the work cycle

The shield mule has the following characteristics:

\section{Good and stability performance.}

The machine operation is flexible, simple, can be in underground tear open outfit, one can be used multiple mine in turn. Machine service deadline last, life can reach more than 20 years, machine failure rate is low.

\section{Wide range of USES.}

It can lifting underground 85 tons the following all the equipment, can also be used as a temporary support, if the crane arm equipped with a bucket, can also be used as a forklift truck in the mine.

\section{Provide better security.}

Useing the shield mule retracement hydraulic support, which changes the traditional use the winch wire rope to pull the old model, reduces the personnel to direct contact with stents, increased security.

\section{Provide higher production efficiency.}

Domestic production of the traditional way, the removal of a hydraulic support is 60 minutes, remove by the shield mule a hydraulic support only about 10 minutes, if the supporting the use of handling equipment, will greatly reduce the labor, to move once, to 140 bracket as a base, only 4 to 7 days to complete.

\section{Test the application}

For the studying the actual application situation of the shield mule, in May 2014 to June 2014, to 8104 Tongxin mine hydraulic support tunneling faces retracement field tracking process was carried out, before a few face prop pulling hoist hydraulic support, evacuation time average 16 days. And 8104 face use the shield mule from hydraulic support, using only 12 days to complete the task. Record the result in the following table 2 - shown in table 5.

\section{Reduce the man-days of branch wood:}

table 2 Reduce the man-days

\begin{tabular}{cccc}
\hline Names & Specification & Decrement & Man-days \\
\hline \multirow{2}{*}{ Square timbers } & $\begin{array}{c}\text { length } \times \text { Width } \times \text { thickness }=1500 \times 200 \times 200 \mathrm{~mm} \\
\text { length } \times \text { Width } \times \text { thickness }=1500 \times 200 \times 200 \mathrm{~mm}\end{array}$ & 3000 & 300 per \\
\hline Summation & & 6000 & 300 per \\
\hline
\end{tabular}

Reduce the square timbers compared with the original practices: $240+180=420 \mathrm{~m}^{2}$

\section{Increase the material:}

table 3 Increase the material

\begin{tabular}{ccc}
\hline Names & Specification & Number \\
\hline Log & length $4.0 \mathrm{~m}, \Phi 200 \mathrm{~mm}$ & 496 \\
Capital & $1300 \times 200 \times 100 \mathrm{~mm}$ & 248 \\
\hline
\end{tabular}

Summation: $62.3+6.45=68.75 \mathrm{~m}^{2}$ 。

\section{Save time and man-days with shield mule:}

Prop pulling hoist is used to drag hydraulic support in the original way, and now shield mule is used, which can reduce the artificial wire rope, save the time of the shelves, and improve the security of the brackets. Use bracket of caterpillar tractor instead of prop-pulling hoist move the shelves cover frame, is a leap of the shelves method. 
table 4 Save time and man-days

\begin{tabular}{clcc}
\hline Names & Specification & Number & Time \\
\hline Prop pulling hoist & hang、drag、move & 15 per & $30 \mathrm{~min}$ \\
Shield mule & operate、command & 2 per & $10 \mathrm{~min}$ \\
\hline
\end{tabular}

The line will broke and hurt peoplewith prop-pulling hoist, and its scrap after withdraw the hydraulic support.

Using shield mule, which stability is good, big traction, can automatic translation and rotation frame, easy to operate.

Thespeed doubled, pulled frame artificial reduced two-thirds (1060). And security is greatly increased.

\section{Save the pigsty combined artificial and material cost:}

table 5 Save cost

\begin{tabular}{ccc}
\hline Names & Specification & Number ( million yuan) \\
\hline Man-days cost & $1660 \times 522.8$ & 86.7964 \\
Material cost & $(420-68.75) \times 5000 \times 1.17$ & 205.48125 \\
Electromechanical cost & $82.6+38-14.1$ & 106.5 \\
Summation & & 398.37765 \\
\hline
\end{tabular}

To save man-days: $600+1060=1660$ per, one man-day about 522.8 (yuan) , man-days cost $1660 \times 522.8=867964$ yuan all told;

Save the pigsty combined artificial and material cost $2054812.5+867964=2922776.5$ yuan all told;

Mechanical and electrical input costs of 8104 working face is RMB 826000. Prop-pulling car equipment repair cost is RMB 380000. Because the stents tractor from 8104 face machine, removes prop pulling car equipment repair costs, withdraw after 6 days in advance at the same time, greatly saving the electrical input cost, invest 141000 yuan only, therefore, mechanical and electronic aspects save money $+38-14.1=82.61 .065$ million yuan.

In short, the double shield shelves method improvement and stent introduction and use of the tractor, retreat for six days earlier than the original time, save the wood about 6000 (420 fang), save man-days 1660 about RMB 860000, plus the electromechanical save cost, save money RMB 3983776.5 .

By the above result shows:

(a) 8104 face from on May 22, 2014 to June 18, smoothly completed the move to retreat, fully shows the effectiveness of process optimization and applicability, stop for future similar conditions of fully-mechanized caving mining supporting design has a guiding significance.

(b) With Tongxin coal mine 8104 working face by adopting the method of multi-channel double shield retreat, and creative use of the United States for the first time in the world the most advanced bracket crane car withdraw support, rapid, efficient, energy saving, consumption reduction, save money about RMB 400000.

(c) Optimized, with fully-mechanized caving hydraulic support's retreat Tongxin mine, more than half a month in general on the basis of the shortened four days, to the extractive cohesion arrangement created valuable time, completed a mission impossible, created a miracle after another, in the future work must adhere to scientific and technological progress as the first productivity, continuous reform and innovation.

\section{Conclusion}

Shield mule's application has solved the problem of hydraulic support retracement in Tongxin, simplified equipment operation system of hydraulic support the relocation, eliminated the unsafe factors that caused by wire rope broken rope and rope skipping, reduced the staff input, reduced the work intensity, ensured the safety of the personnel, improved the mechanization level of the fully mechanized equipment relocation, and increased the mine economic benefit. 


\section{Acknowledgements}

This work was financially supported by the DATONG COAL MINE GROUP science and technology development plans.

\section{References:}

[1] Guo-dong ZHANG. Coal Mine Machinery, 2009, 37(7): 93-96. In Chinese

[2] Hui-hui XIA, Jian-zhong CHEN, Xing-quan LIU, etc. Coal mining Technology, 2013, 18(3): 37-39. In Chinese

[3] Xue-cheng WANG. Coal Science and Technology, 2014, 35(3):134-135. In Chinese

[4] Gang WU. Coal Mine Machinery, 2014, 35(6):167-169. In Chinese

[5] Kai CHANG. Coal Mine Machinery, 2009, 14(6):28-29. In Chinese

[6] Li-qing DANG, Feng-qi BAO, Guo-hua LI. Coal Mine Machinery, 2013, 34(12):182-183. In Chinese

[7] Tao SONG. Coal Mine Machinery, 2015, 36(2) : 20-21. In Chinese

[8] Qing-hua JIA. Coal Science and Technology, 2013, 41(Z) : 95 - 97. In Chinese 